\title{
INTERNAÇĀ() CONJUNTA: CRITERIOS PARA DECISÃO SOBRE QUE MÃES PODERÃO ACOMPANHAR SEUS FILHOS DURANTE A HOSPITALIZAÇÃO
}

\author{
Edelia del Pilar Neira Huerta*
}

NEIRA HUERTA, E. del P. Internação conjunta: critérios para decisão sobre que mães poderão acompanhar seus filhos durante a hospitalização. Rev. Esc. Enf. USP, São Paulo, 18(1):13-21, 1984.

Com o objetivo de oferecer subsidios ds enfermeiras de unidades que permitem a presença da mãe junto a seu filho doente, a autora analisa e comenta os critérios utilizados pelas enfermeiras de uma unidade pediatrica, para decidir quais as mães que poderão acompanhar seus filhos durante a hospitalização, fazendo também algumas considerações sobre as acomodações oferecidas ds mães em sistema de internação conjunta mäe-filho.

\section{INTRODUÇÃO}

Devido ao reconhecimento dos efeitos nocivos que a interrupção do relacionamento mãe-filho provoca em ambos, tem sido amplamente recomendada a manutenção deste vínculo durante a difícil experiência de hospitalização da criança.

Atendendo a estas recomendações vemos que os hospitais pediátricos aumentam a frequiência e duração dos horários de visita, tendo alguns, inclusive, adotado o sistema de internação conjunta mãe-filho em suas unidades, permitindo, desta forma, a presença contínua da mãe junto a seu filho doente.

A adoção deste sistema vem apresentando algumas dificuldades para as enfermeiras de uma unidade de um hospital governamental, na qua] acompanho alunos em seu trabalho prático; entre outras, a dificuldade de decidir que mães poderão acompanhar seu filho, durante a hospitalização, dificuldade esta agravada pelo fato de considerarem inadequadas as acomodações que são oferecidas pela unidade às mães.

Acreditando ser este um problema comum a muitas enfermeiras de unidades pediátricas que têm adotado tal sistema, e com o objetivo de oferecer-lhes subsídios que as auxiliem na sua resolução, propus-me neste trabalho, a analisar e comentar os critérios utilizados pelas enfermeiras antes citadas, como também fazer algumas considerações em relação às acomodações que a referida unidade oferece.

- Enfermeira. Auxiliar de Ensino do Departamento de Enfermagem Materno-Infantil e Psiquiatrica da Escola de Enfermagem da USP - disciplina Enfermagem Pedíatrica. 
Até pouco tempo atrás era oferecida a todas as mães que assim o desejassem, a oportunidade de acompanhar seu filho doente na unidade, oportunidade esta que segundo a opinião das enfermeiras, estava sendo aproveitada por grande número de mães apenas para resolver seus problemás sócio-econômicos - mães de outras cidades ou de outros estados que não possuiam recursos econômicos nem familiares em São Paulo.

Para evitar que isto continuasse a ocorrer, as enfermeiras da unidade, a quem atualmente cabe a decisão da permanência ou não da mãe junto à criança, passaram a adotar um novo critério baseado na necessidade que a criança tem de sua mãe, necessidade esta que é avaliadc na admissão da criança ao hospital.

Segundo a opinião destas enfermeiras, "criança que necessita de sua mãe é aquela que se apresenta agitadíssima durante a admissão; que chora muito, grita pela mãe enquanto a atendente lhe dá banho e a mãe é entrevistada pela enfermeira; criança que esperneia muito durante o exame físico ou que apresenta qualquer outro problema, como por exemplo problema neurológico, e cuja mãe tem um jeito todo especial para lidar com ela; criança muito grave ou com prognóstico fechado. Também no caso de mãe e filho falarem idioma estrangeiro, quando ninguém exceto a mãe entende o que a criança diz, então a mãe é necessária como intérprete. Tudo isto independe da idade da criança; pode ser, inclusive, adolescente."

Uma vez verificada a necessidade da criança de ter sua mãe an lado junto "a mãe é informada que seria bom ela ficar com a criança e verifica-se se ela tem problemas que não lhe permitam ficar, como seria outros filhos em casa ou a mãe que trabalha."

As enfermeiras relatam, ainda, outras condições em que é permitida a presença da mãe junto a seu filho na unidade: "às vezes acontece de uma criança que fora admitida sem sua mãe, porque no momento da internação não precisava dela, se agrava muito; nesse caso solicitamos à mãe para ficar. Ela pode permanecer enquanto a criança estiver consciente; com criança inconsciente não dá; a mãe, toda nervosa apenas atrapalha."

Analisando estes critérios pode-se ver que nesta unidade é permitida a presença da mãe junto ao filho apenas em situações especiais, como de reações exacerbadas de tensão à hospitalização e estado grave ou fase terminal de doença, e desde que a criança esteja consciente.

De acordo com estes critérios parece-me que, em lugar de ser levada em conta a necessidade que a criança tem de sua mãe, o propósito parece ser o de evitar problemas que a criança, quando separada de sua mãe, poderia criar para a enfermagem da unidade.

Refletindo sobre estes critérios parece-me que os fundamentos que levaram a considerar a permanência da mãe ao lado do filho doente no hospital como benéfica, não apenas para a criança mas também para 
a mãe, não são conhecidos ou compreendidos pelas enfermeiras que os utilizam.

Isto não representa a realidade apenas desta unidade, pois segundo MAC CARTHY ${ }^{11}$, ainda é grande a ignorância por parte do pessoal hospitalar tanto em relação à importância da participação da mãe nos cuidados a seu filho doente, como aos prejuízos de separá-los nesta difícil experiência.

\section{FUNDAMENTOS DA INTERNAÇÃO CONJUNTA MĀE-FILHO}

Grande número de autores tem apontado o vinculo mãe-filho como um fenômeno de reciprocidade, uma relação simbiótica de interações mútuas, da qual tanto uma como o outro obtêm, como resultado, elementos que favorecem seu desenvolvimento pessoal, sendo portanto, uma necessidade para ambos.

BOWLBY ${ }^{1}$ afirma ser essencial à saúde mental da criança a vivência de uma relação calorosa, íntima e contínua com a mãe, ou substituta permanente, na qual ambos encontrem satisfação e prazer.

Segundo KLAUS \& KENNELL ${ }^{9}$ a mãe tem necessidade de sentir que pertence a seu filho e, somente quando possuidora deste sentido, ela será capaz de prover cuidados maternais à criança.

Para JENKINS \& WESTHUS ${ }^{8}$ um relacionamento adequado é vita] tanto para o crescimento e desenvolvimento da criança como para a saúde e auto-estima da mãe.

Na literatura tem sido bem estabelecido que separar a criança da mãe pode ter efeitos negativos em sua saúde emocional e mental.

BOWLBY ${ }^{1}$ é enfático ao afirmar que a privação parcial da mãe pode resultar em distúrbios nervosos e em personalidade instável, devido a que a criança, particularmente a criança pequena, não tem capacidade para lidar com as emoções e impulsos que a separação da mãe provoca nela.

Para RUBENSTEIN *, a criança privada de uma fıgura materna adequada, não apenas carece de estímulos afetivos e sociais, mas também carece de estímulos que lhe permitam exercitar suas funções psico-motoras emergentes, sofrendo, portanto, também de privação ambiental.

São numerosos os estudos que enfatizam relacionar-se a ausência da mãe, ou de uma substituta apropriada, a dificuldades emocionais que a criança apresenta durante a hospitalização.

ROBERTSON ${ }^{16}$, BOWLBY ${ }^{1}$ e PRUGH et alii ${ }^{15}$ apontam a separação da mãe como a principal causa das reações da criança à hospitali-

- Apud. BRAlic 2. 
zação. Eles afirmam que crianças entre as idades críticas de 0 a 5 anos passam por vários estágios de ansiedade.

ROBERTSON ${ }^{16}$ descreve três fases seqüenciais na resposta emocional da criança à separação da mãe: protesto, desesperança e negação, considerando esta última como muito séria e indicativa de relacionamento mãe-filho severamente prejudicado.

Muitas crianças, separadas de suas mães durante o periodo da internação hospitalar, apresentam também dificuldades emocionais ao retornar ao ambiente familiar.

FREIBERG ${ }^{5}$ enumera os seguintes comportamentos novos da criança ao retornar a seu lar após uma hospitalização: demanda de maior atenção da mãe; tiques ou maneirismos; temores novos; choro quando a mãe se separa dela por curtos períodos; ciúmes de outro(s) membro(s) da família; retraimento e acanhamento; insônia; pesadelos; comportamentos hostis para com os pais; hábito de carregar ou segurar cobertores ou brinquedos; crises de birra e hiperatividade.

Numerosos autores apontam a presença da mãe junto ao filho doente como a melhor medida de prevenção dos efeitos nocivos da hospitalização na criança.

NOLAN ${ }^{14}$ afirma que a prevenção de traumas residuais da hospitalização na criança nunca poderá ser total, já que a própria doença provoca efeitos nocivos; mas, assegura a autora, com certeza a internação conjunta mãe-filho é o método mais efetivo para reduzir os traumas psicológicos da hospitalização na criança.

Segundo HARDGROVE \& RUTLEDGE ${ }^{?}$ os pais são a melhor esperança de fazer da hospitalização da criança uma experiência útil; sua presença normaliza o ambiente reduzindo a ansiedade da criança e assegurando-lhe continuidade no seu desenvolvimento.

Existem na literatura alguns estudos que demonstram as vantagens que a presença da mãe junto ao filho doente tem para a criança.

FAGIN ${ }^{3}$ fez um estudo comparativo de certos aspectos do comportamento pré e pós hospitalização de crianças de 18 a 36 meses de idade, cujas mães não permaneceram junto à criança, e comparoı os resultados com o comportamento pré e pós internação de crianças cujas mães as acompanharam durante a experiência hospitalar. A autora verificou que as crianças do primeiro grupo apresentaram regressão marcada, manifestada através de reações a curtas separações da mãe, dependência emocional, alterações do apetite e dos hábitos de alimentação, distúrbios do sono e regressão no controle esfincteriano. Por outro lado, o grupo de crianças que fora atendido por suas mães não apresentou mudanças regressivas significativas no seu comportamento, significando isto, para a autora, que o desenvolvimento não fora prejudicado pela experiência hospitalar. 
MAHAFFY ${ }^{12}$, estudando os efeitos da hospitalização em crianças admitidas para tonsilectomia e adenoidectomia, observou que as crianças acompanhadas pela mãe no dia da cirurgia apresentavam menor incidência de náuseas e vómitos, de febre e de choro e que a hidratação oral era significativamente maior. Observou, também, que a recuperação destas crianças era mais rápida, com menor número de complicações e que elas demonstravam menores alterações do comportamento durante e após a hospitalização.

Vários trabalhos mostram que a manutenção do relacionamento mãe-filho durante a experiência de hospitalização da criança, além de ser uma necessidade para ambos, oferece vantagens, não apenas para a criança, mas também para sua mãe.

Segundo WOFFINDIM ${ }^{20}$, na situação de internação conjunta a mãe tem a oportunidade de sentir que ajuda de maneira construtiva na recuperação de seu filho, o que provoca nela sentimento de competência e realização.

FLETCHER ${ }^{4}$ ressalta, como uma das principais vantagens da internação conjunta, a oportunidade que é dada à mãe de se sentir física e psicologicamente disponivel para seu filho doente e de saber que compartilha de sua difícil experiência de hospitalização.

VERMILION et alii ${ }^{10}$, após experiência de oito anos em unidades que permitem a presença constante dos pais junto ao filho doente, afirma que os pais adquirem maior competência no cuidado de seus filhos e os laços entre eles são reforçados.

Continuando a análise dos critérios utilizados pelas enfermeiras já mencionadas, na decisão de que mães podem permanecer junto a seu filho na unidade, parece-me que elas ainda não identificaram muitas das vantagens que a internação conjunta representa para a equipe hospitalar.

VAN DER SHYFF ${ }^{18}$ destaca as seguintes vantagens para o pessoal hospitalar, quando a mãe é envolvida no cuidado de seu filho hospitalizado:

- as enfermeiras são liberadas para dedicar um tempo maior à assistência daquelas crianças que estão separadas de seus pais;

- representa uma oportunidade ideal para educar os pais;

- permite maior grau de interação entre a equipe e os pais;

- estudantes e profissionais da saúde podem observar a interação mãefilho e a criança como paciente em um ambiente mais real;

- pais interatuam ajudando, ensinando e dando apoio à criança, promovendo assim saúde mental no ambiente hospitalar.

SPENCE * afirma que permitir à mãe ser internada com seu filho doente tem também vantagens para as enfermeiras, as quais, segundo o

- Apud. BOWLBY 1. 
autor, aprendem muito em contato com o que asmães têm de melhor, não apenas sobre como lidar com crianças, mas também sobre a própria vida.

Segundo NOLAN ${ }^{14}$ a presença da mãe é de grande valor para a enfermeira, tanto na identificação das necessidades da criança como na decisão da maneira mais adequada de atendê-las.

Para MARLOW ${ }^{13}$, a situação de internação conjunta oferece às enfermeiras uma excelente oportunidade para: detectar e intervir em qualquer problema de relacionamento mãe-filho; observar e avaliar as atitudes, habilidades e técnicas das mães; e principalmente desenvolver e ganhar grande experiência nas habilidades de comunicação e ensino.

MAC CARTHY ${ }^{11}$ e VERMILION et alii ${ }^{19}$ afirmam que a permanência da mãe junto ao filho hospitalizado reduz a incidência de infecções cruzadas porque a criança é manipulada por um número significativamente menor de pessoas.

\section{QUAIS MÃES DEVEM ACOMPANHAR SEU FILHO NO HOSPITAL?}

A base dos critérios, objeto desta análise, ou seja, a necessidade que a criança tem de sua mãe, junto com meu reconhecimento de que todas as crianças, em maior ou menor grau, necessitam de sua mãe, levou-me às seguintes perguntas:

- que crianças são particularmente vulneráveis à separação da mãe?

- que crianças têm maior necessidade de sua mãe durante a hospita. lização?

Numerosos autores são unânimes em afirmar que crianças menores de 5 anos não devem ser separadas de sua mãe durante a crise que a hospitalização representa para a criança e sua família (ROBERTSON ${ }^{16}$, BOWLBY ${ }^{1}$, SPENCE ${ }^{*}$, PRUGH et alii ${ }^{15}$ e FAGIN ${ }^{3}$ ).

Segundo MAC CARTHY ${ }^{11}$, todas as crianças, inclusive aquelas maiores de 5 anos, são especialmente lábeis à separação da mãe ao enfrentar uma hospitalização, quando:

- seu desenvolvimento emocional é imaturo;

- nunca antes experimentaram separação de sua mãe;

-- sua capacidade de expressão e/ou compreensão verbal é precária para sua idade cronológica;

- a região corporal afetada provoca grande ansiedade, como boca, olhos e região anal e/ou genital; e

* Apud. BOWLBY 1 
- diante de crise ou mudança recente no ambiente familiar, como nascimento de um irmão, mudança de residência, desavenças entre membros da familia, morte de uma pessoa querida ou de um animal de estimação, ingresso à escola, entre outros.

Vemos assim a importância de considerar, explorar e avaliar estes aspectos no processo de admissão da criança ao hospital para determinar em que grau a criança necessita da presença da mãe durante a experiência de hospitalização.

Por outro lado, reconhecendo que todas as mães têm necessidade de seu filho e se beneficiam com a experiência de internação conjunta, pergunto-me: é aconselhável permitir a todas as mães, inclusive àquelas altamente ansiosas, compartilhar com seu filho a experiência de hospitalização?

FAGIN ${ }^{3}$ afirma que todas as mães, particularmente as de crianças pequenas, exceto aquelas claramente psicóticas, devem ser permitidas, e certamente encorajadas, a permanecer com seu filho durante a hospitalização da criança.

ROBERTSON * afirma que as mães invariavelmente conseguem amenizar sua ansiedade quando estão com seu filho.

\section{ACOMODAÇŌES EM SISTEMA DE INTERNAÇÃO CONJUNTA}

Como já referira no início deste trabalho, as enfermeiras consideram que sua unidade não possui acomodaçōes adequadas para a permanência constante das mães. Essa unidade oferece as seguintes acomodações:

- poltronas reclináveis, com suas respectivas banquetas para apoio dos pés, que são instaladas ao lado do leito das crianças;

- uma pequena sala onde as mãos podem tomar suas refeições, descansar e fumar;

- um banheiro com chuveiro, localizado ao lado da sala acima referida e

- um telefone público na portaria do hospital.

Além disso são fornecidas quatro refeições diárias às mães: desjejum, composto de café ou chá com leite e pão com manteiga; almoço; jantar, em que é oferecida sopa e pão; e um lanche às 21 horas, em que novamente é oferecido café ou chá com leite e pão com manteiga; as mães têm a possibilidade de repetir qualquer dessas refeições, como, também, aquelas que possuem recursos econômicos, de tomar algum lanche nas proximidades do hospital.

$\mathrm{Na}$ literatura encontramos referência sobre uma ampla gama de acomodações para as mães que acompanham seu filho durante a hospitalização, desde os mais simples, como colchonete, ou apenas cadeira

- Apud. FAgin 3 
para conforto da mãe, até os mais sofisticados tipo "kitchenette" equi padas inclusive com telefone e aparelho de T.V. (HARDGROVE \& KERMOIAN $^{6}$, LISBOA ${ }^{10}$, HARDGROVE \& RUTLEDGE ${ }^{7}$, NOLAN ${ }^{14}$, VERMILION et alii ${ }^{19}$ e WOFFINDIM ${ }^{20}$ ).

NOLAN ${ }^{14}$, que vivenciou a experiência de acompanhar sua filha de quatorze meses durante sua hospitalização, é enfática ao declarar que as mães nesta situação estão muito preocupadas com seu filho doente e não se preocupam com conforto para elas. A autora acrescenta que a acomodação mais confortável que ela poderia imaginar seria um colchonete para ser estendido ao lado do leito da criança à noite.

A mesma autora afirma ter absoluta certeza de que nenhuma mãe esperaria outras comodidades, como refeições, por exemplo. Para NOLAN ${ }^{14}$ a oportunidade de estar perto e de oferecer apoio ao próprio filho é a melhor recompensa.

Durante uma conversa com uma mãe que compartilhava a experiência de hospitalização de sua filha, tive a oportunidade de confirmar a afirmação de NOLAN" ${ }^{4}$. Essa mãe disse-me: "É, a senhora está certa; estou cansada... não é fácil dormir nesta poltrona e a comida é um pouco fraca, mas nada disso tem importância; eu ficando aqui está tudo ótimo!"

Podemos, assim, junto com ROGERS ${ }^{17}$, comprovar que ninguém melhor do que o próprio indivíduo conhece seus problemas e suas necessidades.

Através dos elementos apresentados neste trabalho podemos concluir que, como enfermeiras pediátricas, não devemos decidir que mães poderão gozar o direito de permanecer junto a seu filho e de participar de seus cuidados, ou decidir que crianças poderão gozar o direito de ter sua mãe junto a si durante a hospitalização, nem tampouco decidir se as acomodações oferecidas às mães são adequadas ou não. Cabe a nós na admissão da criança ao hospital, zelar para que o relacionamento mãe-filho seja mantido durante a hospitalização da criança:

- encorajando as mães a permanecerem com seus filhos, isto é, esclarecendo-as em relação aos benefícios que sua presença no hospital terá para a criança;

- encorajando-as a verbalizar seus sentimentos, preocupações e problemas, dando-lhes o nosso apoio e aceitação em sua decisão de permanecer ou não, confiando sempre em sua capacidade de sentir, pensar e agir na resolução de seus problemas, particularmente quando em benefício de seu próprio filho.

Principalmente, cabe a nós, criar o clima que facilite a mudança de atitudes da equipe hospitalar em relação à presença da mãe nos ambientes pediátricos, de maneira que, em um futuro próximo, a adoção do sistema de internação conjunta mãe-filho seja a realidade de toda unidade pediátrica, realidade esta que, como conseqüência natural, provocará melhora nas acomodações para as mães. 
NEIRA HUERTA, E. del P. Rooming-in: which mothers may remain with their sick children during hospitalization in Pediatric Units? Rev. Esc. Enf. USP, São Paulo, 18(1):13-21, 1984.

Pediatric nurses for decision making about wich mothers may accompany their sick children during hospitalization, in a unit that allows rooming-in, are analized by the author. Some considerations are also made about accomodations offered to these mothers.

\section{REFERENCIAS BIBLIOGRÅFICAS}

1. BOWLBY, J. Cuidados maternos e saúde mental. São Paulo, Martins Fontes, 1981.225 p.

2. BRALIC, S. Estimulación temnrana: importancia de ambiente para el desarrollo del niño. Santiago, UNICEF, 1978.276 p.

3. FAGIN, C. M. Pediatric rooming-in: its meaning for the nurse. Nurs. Clin. North Amer., Philadelphia, 1(1):83-93, Mar. 1966.

4. FLETCHER, B. Rooming-in: a reassessment. Matern. Child Nurs. J., Pittsburg, 10(2): 85-98, summer 1981.

5. FREIBERG, K. How parents react when their child is hospitalized. Amer. J. Nurs., New York, $72(7): 1270-72$, July 1972.

6. HARDGROVE, C. \& KERMOIAN, R. Parent-inclusive pediatric units: a survey of policies and practices. Amer. J. Publ. Heath., New York, 68(9):847-50, Sept. 1978.

7. \& RUTLEDGE, A. Parenting during hospitalization. Amer. J. Nurs., New York, 75(5) :836-38, May 1975 .

8. JENKINS, R. L. \& WESTHUS, N. K. The nurse role in parent-infant bonding: overview, assessment and intervention. JOGN Nurs., Hagerstown, 10(2):114-8, Mar./Apr. 1981.

9. KLAUS, M. \& KENNELL, J. La relación madre-hijo. Buenos Aires, Panamericana, 1978. 228 p.

10. LISBOA, A. M. Programa de hospitalização conjunta măe-fillho. J. Pediat., Rio de Janeiro, 38(7-8):191-94, jul./ago., 1973.

11. MAC CARTHY, D. The under fives in hospital. Nurs. Times, London, 77(30; suppl.): 22-28, July 1981.

12. MAHAFFY, $P$. The effects of hospitalization on children admitted for tonsillectomy and adenoidectomy. Nurs. Res., New York, 14(1):12-19, Mar. 1965.

13. MARLOW, D. Textbook of pediatric nursing. 5. ed., Phlladelphia, Saunders, 1977.949 p.

14. NOLAN, H. Hospitalization of infants and pre-schoolers-observations and reflections of by a live-in mother. Lamp, Sidney, 38(8):29-35, Aug. 1981.

15. PRUGH, D. et alii. A study of the emotional reactions of children and families to hospitalization and illness. Amer. J. Orthopsychiatry, New York, 23(1):70-106, Jan. 1953.

16. ROBERTSON, J. Some responses of young children to the loss of maternal care. Nurs. Times, London, 49(16):382-86, Apr. 1953.

17. ROGERS, C. R. \& ROSENBERG, R. L. A pessoa como centro. São Paulo, E.P.U., EDUSP, 1977. 228 p.

18. VAN DER SHYFF, G. The role of parents during their child hospitalization. Austral. Nurs. J., Port Adelaide, 8(11):57-61, Jun. 1979.

19. VERMILION, B. et alii. The effective use of parent-unit for infants on the surgical service. J. Pediat. Surg., New York, 14(3):321-24, June, 1979.

20. WOFFINDIM, K. E. Children and their parents in hospital. Nurs. Times, 77 (suppl. 8): 31-32, Mar. 1981. 